\title{
Estéticas de vanguardia, cultura política y poéticas coloquiales en las revistas de la izquierda intelectual sesentista
}

\author{
Mariana Bonano \\ Universidad Nacional de Tucumán (UNT, \\ Argentina); CONICET.
}

\section{Resumen}

El presente artículo aspira a indagar en los proyectos de escritores constituidos en torno de tres publicaciones periódicas de la década de 1960 en Argentina, Zona de la poesía americana, El Barrilete y Hoy en la cultura, focalizando una dimensión común a todos ellos: el planteo programático de redefinición del trabajo poético, o bien del «problema de la referencialidad en la escritura» (Porrúa, 1992), en pos de la búsqueda de una forma nueva de hablar sobre el referente y desde una colocación contraria a la de las estéticas de vanguardia. Intenta inquirir en esta cuestión mediante el análisis y puesta en diálogo de textos programáticos, ensayos acerca de la teoría del arte, indagaciones sobre la relación entre el poeta y el poema, recogidos en las páginas de las tres revistas. Esta labor posibilitará en particular indagar en la vinculación que Zona..., El Barrilete y Hoy en la cultura establecen con la estética del surrealismo francés y con algunos de sus cultores más conspicuos.

Palabras clave

revistas argentinas, izquierda literaria, poéticas coloquiales y estéticas de vanguardia, cultura política 
Abstract

Avant-Garde Aesthetics, political culture and colloquial poetics in the intellectual left-wing publications of the 1960s

This article aims to examine writers' projects that result from three periodical publications ofther96os in Argentina, Zona de la poesíaamericana, El Barrileteand Hoy en la cultura, focusing on a common dimension to all of them:the programmatic approach to the redefinition of poetic work, or the "problem of referentiality in writing" (Porrúa, 1992), in pursuit of a new way of talking about the referent and from a placement contrary to that of the Avant-GardeAesthetics. It discusses this aspect from the examination of programmatic texts, essays on the theory of art, and inquiries about the relationship between the poet and the poem, collected in the pages of these three journals. This will allow for the research of the linkage between Zona..., El Barrilete and Hoy en la cultura, with the aesthetics of French surrealism and with some of its most relevant figures.

\section{Resumo}

\section{Estéticas de Vanguarda, cultura política e poéticas coloquiais nas revistas da esquerda intelectual dos anos sessenta}

$\mathrm{O}$ presente artigo tem como objetivo indagar nos projetos de escritores constituídos em relação a três publicaçóes periódicas durante a década de 1960 na Argentina, Zona de la Poesía Americana, El Barrilete e Hoy en la cultura, pondo foco em uma dimensão comum a todas elas: a abordagem programática de redefinição do trabalho poético, ou do "problema de referencialidade na forma de escrever» (Porrúa, 1992), em busca de uma nova maneira de falar sobre o referente e desde um posicionamento contrário ao das estéticas

\section{Keywords:}

argentine journals, literary left, colloquial poetics andavant-garde aesthetics, political culture

Palavras-chave:

revistas argentinas, esquerda literária, poéticas coloquiais e estéticas de vanguarda, cultura política 
de vanguarda. Tenta pesquisar esta questão através da analise e diálogo de textos programáticos, ensaios sobre a teoria da arte, indagaçóes na relação entre o poeta e o poema, coletados nas páginas das três revistas. Este trabalho permitirá, em particular, pesquisar a relação que Zona..., El Barrilete e Hoy en la cultura, estabelecem com a estética do surrealismo francês e com alguns dos seus cultores mais ilustres.

\section{Punto de partida ${ }^{1}$}

El presente trabajo se enmarca en una indagación de mayor alcance, llevada a cabo por nosotros entre 2012 y $2016, y$ centrada en los proyectos de escritores reunidos en torno de tres publicaciones periódicas de la década de 1960 en Argentina: Zona de la poesía americana, El Barrilete (primera época) y Hoy en la cultura. ${ }^{2} \mathrm{La}$ investigación propuso como una de las hipótesis de partida que los programas de poesía impulsados por los hacedores en las páginas de las tres revistas mencionadas poseen, más allá de las diferentes procedencias estéticas e ideológicas de sus animadores, una marca común: el gesto crítico de privilegiar las llamadas "poéticas coloquiales», caracterizadas, entre otros rasgos, por un discurso poético permeable a diversos discursos sociales (narrativa, canciones de tango, lengua oral y coloquial), así como por la incorporación al poema de los elementos de la vida cotidiana y/o del contexto sociopolítico. ${ }^{3}$ En vinculación con ello, los escritores nucleados en Zona..., El

1 Una primera versión de este trabajo apareció en 2013 bajo el título "Pervivencias y discontinuidades de la vanguardia en revistas literarias argentinas de 1960". El artículo difundido en el marco del XVII Congreso Nacional de Literatura Argentina, llevado a cabo en Comodoro Rivadavia, fue recogido luego en las Actas del evento, compiladas por Silvia Bittar y editadas por Universitaria de la Patagonia en forma de E-Book.

2 En efecto, las tres revistas que se abordan aquífueron objeto de estudio de la investigación desarrollada en el marco de nuestro trabajo como Investigadora Asistente del CONICET. El plan desplegado a lo largo de ese período focalizó las estéticas así como las representaciones y operaciones críticas en torno a lo poético presentes en artículos programáticos, escritos ensayísticos y textos líricos ofrecidos en revistas dedicadas al género, o bien en publicaciones de índole cultural que aunque no están destinadas específicamente a la poesía, conceden a este género un lugar privilegiado.

$3 \mathrm{La}$ actitud de apertura del poema a la realidad cotidiana, social o política es identificada por la crítica sobre el período con la práctica de la "poesía coloquial" o "conversacional". En la Antología de la poesía de 1960 preparada por Alfredo Andrés, El 60 (1969), se propone también la categoría de 
Barrilete y Hoy en la cultura inscriben sus proyectos dentro de una búsqueda más abarcadora, consignada también por la bibliografía respecto del programa delineado por otras revistas literarias y culturales de la izquierda intelectual del período: la voluntad de integración de la práctica poética a la sociedad. De allí el planteo que tales grupos líricos impulsan acerca de la necesidad de conformación de una "poesía autónoma» animada por el propósito de una mayor vinculación con el conjunto social que la alcanzada por los movimientos de vanguardia precedentes. Estos últimos constituyen, a ojos de aquellos,tendencias instauradoras de una actividad simbólica circunscripta a un ámbito cultural estrecho, así como de una poesía epigonal respecto de modelos extranjeros.
Desde una colocación contraria a la de las estéticas de vanguardia, los poetas coloquiales de los sesentas innovan al perseguir una forma nueva de hablar sobre el referente.Tal redefinición se sitúa, sin embargo, en un campo de tensiones originadas por la coexistencia de dos principios que en primera instancia resultan antagónicos: por una parte, según advierte Miguel Dalmaroni (1993), el «coloquialismo» se contrapone polémicamente a la estética regida por las «normas más estrictas de la lírica en tanto género más o menos codificado, ligado especialmente a la tradición que inauguran los románticos y que alcanzaría su realización paradigmática con los simbolistas franceses y -en algunos aspectos - con el trabajo de experimentación de algunas de las vanguardias eu-

"poesía del realismo crítico" para caracterizar a las corrientes líricas de los sesentas.Algunos rasgos pueden ser delimitados a propósito de este tipo de poéticas: narrativización de los versos; desmitificación de la figura del poeta y de la poesía, frecuentemente mediante la recurrencia al humor, al sarcasmo, a la ironía; recurrencia a vocablos y modismos propios de la lengua oral y conversacional; incorporación al poema de otras voces y discursos sociales (letras de tango, narrativa, jingles publicitarios, canciones de moda, discurso histórico), y de referencias literarias y culturales que permiten inscribir al escritor en una tradición y en una realidad histórica precisas; apelación a la segunda persona o a la primera del plural, con el fin de acercar el sujeto lírico al lector e involucrar a este último en una reflexión colectiva. Para el estudio de las poéticas coloquiales en Hispanoamérica cfr., entre otros, Carmen Alemany Bay (1997). Para el de la poesía coloquial en Argentina, cfr. los de Horacio Salas (1975), Eduardo Romano (1983), Ana Porrúa (1987; 1992; 2001; 2002), Daniel Freidemberg (1999a), Miguel Dalmaroni (1993; 2002), Daniel García Helder (1999), entre otros. De acuerdo con el relevamiento realizado, se advierte que más allá de lo señalado por los trabajos críticos, son los propios poetas quienes contribuyen, mediante su labor reflexiva, a sentar las bases de una mirada que identifica la producción lírica de esta etapa con una línea de "poesía conversacional" o "coloquial". 
ropeas» (I6); por otra, retoma uno de los gestos inscriptos en "una genealogía cuya procedencia se remonta al surgimiento de las vanguardias históricas» (Calabrese): el imperativo de fundir la poesía con la vida, o de reconectar intensamente la poesía a la «praxis vital» (Bürger).

Tomando en cuenta las precisiones antes realizadas, el presente trabajo aspira a evaluar la presencia en las páginas de Zona..., El Barrilete y Hoy en la cultura, de una dimensión que las atraviesa por igual: la recepción de las poéticas de vanguardia desde un posicionamiento que, según se explicitó arriba, polemiza con el ideario estético representado por estas tendencias. Tal dimensión será examinada en relación tanto con revistas dedicadas con exclusividad a la poesía (Zona... y El Barrilete), como con una publicación de índole cultural que aunque no está destinada específicamente a la poesía, concede a este género un lugar privilegiado (Hoy en la cultura).

\section{Revolución surrealista y transformación política en Hoy en la Cultura}

Heredera de una empresa cultural anterior, ${ }^{4}$ la revista Hoy en la Cultura nace en noviembre de I96I y a partir de entonces, edita 29 números a lo largo de cinco años hasta su cierre definitivo en julio de i966. Pedro Orgambide es junto a Raúl Larra y David Viñas, el impulsor del nuevo emprendimiento. ${ }^{5}$ Perfilada desde el editorial que abre su número I como un espacio de encuentro de «las diversas corrientes progresistas del pensamiento y del arte en la Argentina» (I96I), la revista da cabida a la polémica cultural, a la vez que sienta posición respecto tanto del acontecer político nacional y mundial,como de los lineamientos culturales pautados por los gobiernos argentinos que se sucedieron a lo largo del decenio de i960. Ciertos núcleos correspondientes al posicionamiento de la izquierda cultural e intelectual radicaliza-

4 Se trata de la revista Gaceta Literaria, cuyo cierre se produjo en septiembre de 1960 durante el mandato de Arturo Frondizi, a raíz de la clausura gubernamental de la editorial e imprenta Stilcograf.

5 Estos tres nombres permanecen como únicos responsables de la publicación hasta el número 3. A partir del número 4 (julio de 1962), la dirección está a cargo de un consejo de redacción integrado por Orgambide, Larra, Viñas, Luis Ordaz, Rubén Benítez, María Fux y Francisco J. Herrera. A partir del número 9 (julio de 1963), el nombre de Viñas ya no figura dentro de este consejo, y desde el número 11 (diciembre de 1963) se incorporan Fernando Birri, Javier Villafañe y Juan José Manauta. Desde el número 13 (marzo-abril de 1964) hasta el cierre de la revista en julio de 1966, ejerce la dirección Juan José Manauta. 
da del período, ${ }^{6}$ se reiteran en las declaraciones, comunicados y textos que a modo de editoriales, los realizadores formulan a lo largo de las páginas de la colección. ${ }^{7}$ La colocación de las principales figuras, cercanas a los círculos literarios y teatrales del Partido Comunista Argentino, da cuenta del vínculo estrecho y a la vez productivo que el grupo establece con esa fracción de la izquierda. ${ }^{8}$

La preferencia por poemas y autores representativos de las estéticas coloquiales, ${ }^{9}$ o bien, cercanos a estas, va de la mano en la revista de la reivindicación de figuras y temas que el grupo evalúa como constitutivos de una tradición simbólica "popular», aquella que en poesía parte de Carriego y «se prolonga a través de Carlos de la Púa, Contursi, Celedonio Flores, R. González Tuñón, su hermano Enrique, Cadícamo, G. Riccio, Discépolo, Portogalo, Manzi, De Lellis y otros todavía anónimos y otros injustamente postergados» (1964:I4), según se formula en "Tango=Poesía» incluido en el número I6.

Las precisiones arriba realizadas habilitan para establecer que la publicación se coloca en primera instancia en una posición antitética a la adoptada por

6 Cabe precisar aquí que, si bien los principales animadores de esta publicación no tienen afiliación partidaria (la excepción la constituye Raúl Larra, quien militó en el Partido Comunista), adoptan posiciones cercanas a los lineamientos culturales del Partido Comunista Argentino (PCA). Esto se refleja tanto en las polémicas que ellos entablan con otros sectores de la izquierda literaria e intelectual, como en la reivindicación de figuras ligadas al PCA y el fuerte apoyo a la causa de la Revolución Cubana.

7 Aparecen la posición antiimperialista y la prédica a favor del desarme nuclear y armamentístico, la "adhesión apasionada a la Revolución Cubana", el "sostén del laicisismo y de la enseñanza estatal", la "salvaguarda de la libertad de expresión", entre otros. Las expresiones entrecomilladas pertenecen al Editorial del número 1 de la publicación.

8 Respecto del tipo de vínculo que Hoy en la Cultura establece con el PCA, tanto Miguel Dalmaroni (2004) como Francine Masiello establecen que aunque los miembros de la publicación no tienen una militancia orgánica en el partido, se hallan próximos al mismo, en tanto comparten con la revista oficial del PCA, Cuadernos de Cultura, temas, figuras y un canon común. Al respecto Masiello señala que si bien tanto Hoy en la Cultura como su predecesora, Gaceta Literaria, "espoused independent visions, their contributors never the les srevealed a close adherenceto the politics of the Argentine Communist party" (57).

9 La crítica asocia las prácticas de la "poesía coloquial" o "conversacional" a la producción de autores como Juan Gelman (en su primera etapa), Eduardo Romano, Juana Bignozzi, Alberto Szpunberg, Ramón Plaza, Horacio Salas, Roberto J. Santoro, Luis Luchi, Julio Huasi, Daniel Barros, Alfredo Andrés, Andrés Avellaneda, Julio César Sivain, entre otros. Los poetas mencionados y otros nombres más integran las antologías que tanto Alfredo Andrés (1969) como Horacio Salas (1975) consideran representativas de la producción poética de la década de 1960. 
los grupos de la vanguardia estética en cuanto a la forma de concebir lo poético y a las genealogías literarias. En relación con ello, cabe señalar que resultan escasos los poemas de autores de la vanguardia argentina difundidos por Hoy en la Cultura. Por otra parte, los textos ensayísticos dedicados al género lírico, impulsan en la revista un modelo de poesía y de escritor distanciados del paradigma imperante en el decenio de 1950, identificado, como se conoce, con las vanguardias invencio- nista y surrealista, y en particular, con el movimiento de escritores reunidos en torno de la revista Poesía Buenos Aires (1950-1960). . ${ }^{10}$ La impugnación de este último paradigma es realizada por el núcleo lírico ${ }^{\text {II }}$ de Hoy en la Cultura en virtud del principio que rechaza la existencia de una práctica simbólica aislada de la realidad y desvinculada del público. Tal concepción es justamente la que prepondera, según los editores estiman, en el conjunto de la poesía de vanguardia argentina. ${ }^{12}$

10 Mariano Calbi señala a la vanguardia invencionista como una tendencia artística que irrumpe en la escena cultural argentina hacia el año 1944 con la revista Arturo primero y luego, con los cuadernos Invención. Alrededor de estas publicaciones se agrupan no solo poetas, sino también artistas plásticos. Ellos utilizan el término invención, frente a la palabra creación, para caracterizar a sus prácticas, pues consideran que el primero "designa una actividad netamente intelectual" (Calbi, 1999:237). La doctrina invencionista descansa en una crítica radical de los supuestos que hacen posible el arte figurativo, pues considera que el arte es «básicamente irrepresentable y no admite, por lo tanto, que el significado de los signos lo explique y, al hacerlo, lo reduzca a una convención establecida por la sociedad" (237). Por otra parte, la vertiente de la poesía surrealista se identifica en Argentina con tres publicaciones fundadas y coordinadas por Aldo Pellegrini: Qué (1928), Ciclo (1948-1949) y A partir de cero (1952-1953). De esta última experiencia participan, además de Pellegrini, los poetas Enrique Molina, Julio Antonio Llinás y Juan A. Vasco.

11 La sección de poesía está inicialmente a cargo de Héctor Negro, Rosario A. Mase, Julio César Silvain y Alberto Wainer, todos ellos escritores pertenecientes a "El Pan Duro", un núcleo poético conformado en 1954 bajo la tutela de Raúl González Tuñón y vinculado con el espacio político y cultural del Partido Comunista Argentino. En el número 19 (marzo/abril de 1965) se agregan otros nombres a Ios anteriores: Alberto M. Perrone, Julio Calvo Encinar, Miguel Ángel Carballada, Luis Alberto Frontera, Ángel Leiva y Ethel M. Saslavsky. En números posteriores se incorpora a esta nómina Rubén Derlis, Roberto Díaz, Hugo Otero y Oscar Tito. En el número 25 (diciembre de 1965) permanecen estos cuatro últimos nombres más el de Alberto Perrone.

12 Dos artículos recogidos en la revista son significativos al respecto. Ambos exponen en forma explícita una valoración negativa de las estéticas de la vanguardia histórica, en la medida en que consideran que ellas pierden contacto con "la realidad de la vida" y promueven la irracionalidad en el arte. Cfr. "Reflexiones y notas sobre el quehacer poético", de Marcelo Román, incluido en el número 9 (julio de 1963) y «Vanguardia y decadentismo", de V. Strada, perteneciente al número 6 (octubre de 1962). 
La disputa que la revista establece con las estéticas de vanguardia puede ser leída a la luz de las polémicas en torno al realismo emergentes en el período, desplegadas entre los intelectuales de la «nueva izquierda" (Terán) y aquellos otros actores culturales que permanecen cercanos a los lineamientos del Partido Comunista Argentino. En efecto, la presencia tutelar y recurrente en sus páginas del poeta Raúl González Tuñón, constituye uno de los indicadores de las vinculaciones que la publicación establece con el PCA y con una línea de poesía social y combativa. ${ }^{13}$ Una lectura atenta a las intervenciones de ese escritor en la revista, muestra que es justamente él quien dedica más de un artículo a la vanguardia surrealista y a los poetas vinculados con este movimiento. Contra lo que sería dable esperar, su posicionamiento expone una valoración positiva de esa poética, como así también de sus principales signatarios. Dado el peso que González Tuñón adquiere en la publicación, respecto de la cual deviene en uno de los colaboradores permanentes, puede establecerse que las opiniones de este autor son representativas de la posición asumida por el grupo editor.
El texto de su autoría titulado «Permanencia y mito. El surrealismo hoy", recogido en el número I4 (junio de 1964), condensa los núcleos principales de la perspectiva antes expuesta. Dedicado a delinear la trayectoria de Tristán Tzara, González Tuñón rescata la noción de poesía acuñada por la vanguardia dadaísta-surrealista: el poema es un «modo de vivir», y no simplemente "un producto escrito», «una sucesión de imágenes». Reivindica, en relación con ese principio, el espíritu de rebelión de la poesía francesa que, a su entender, se sitúa en el terreno de la vida concreta. Así, el nombre de Tzara es, a los ojos del autor, representativo de "las dos vanguardias", «la del arte y la literatura libres, (...) y la de la lucha por transformar la sociedad, contra todo aquello que afea la vida del hombre» (1964:5). ${ }^{14}$ Esta lectura de la obra y de la vida de Tzara, impulsa a la vez su delimitación en las páginas de la revista, de la vanguardia surrealista como un movimiento estético renovador, y al mismo tiempo, políticamente revolucionario, una praxis transformadora de la realidad cuyo impulso innovador más que operar a nivel formal, afecta las propias condiciones de existencia del poeta.

13 Precisamente, Dalmaroni señala que, hacia la década de 1960, la figura de González Tuñón no sólo se identifica con la del "escritor consagrado", sino mucho más específicamente, con la del "poeta oficial del Partido Comunista argentino" (2012). Las cursivas son del autor.

14 González Tuñón fundamenta esta caracterización en una frase pronunciada por el propio Tzara: "El valor poético más alto es aquél que coincide con la revolución proletaria» (1964:5). 
La militancia política y el espíritu irreverente que González Tuñón encuentra en Tzara, son igualmente reivindicados por él en relación con otros escritores de la vanguardia. En su artículo sobre el creacionista César Vallejo, ${ }^{15}$ traza una línea de continuidad en la adopción de una actitud rebelde por parte del poeta de vanguardia, lo que le permite a la vez construir una genealogía capaz de vincular a la vanguardia martinfierrista argentina con los franceses representados por Víctor Hugo primero y luego, por Baudelaire, Rimbaud, Verlaine, Charles Cros, Alfred Jarry, así como con el dadá-surrealismo y la militancia posterior de Aragón, Desnos, Tzara, Crevel, Eluard. La delimitación de esta genealogía posibilita al autor el rescate del martinfierrismo ${ }^{16}$ en tanto tendencia estética radical y lo habilita simultáneamente a enjuiciar la idea sostenida por otros sectores de la intelectualidad crítica y de Hoy en la Cultura, de la vanguardia como movimiento irracional y escapista. En su consideración de las estéticas de vanguardia, la posición que González Tuńón delinea, resulta por tanto disidente respecto de la orientación dominante de la publicación.

Según señalamos en un trabajo previo de nuestra autoría, ${ }^{17}$ la presencia de voces divergentes en las páginas de Hoy en la Cultura, perfilan a la revista en tanto órgano de la izquierda cultural sesentista cuyo programa literario si bien prioriza una poética en estrecha relación con el contorno, no desdeña la consideración de expresiones líricas latinoamericanas y/o europeas más vinculadas con/o próximas a la experimentación vanguardista. A partir de lo expuesto más arriba, puede establecerse que el grupo editor adhiere a una concepción de lo poético en tanto praxis abierta al entorno social, al tiempo que expresa una voluntad de transformación de este mismo entorno, pero no acuerda, sin embargo, con la

15 "Crónica de César Vallejo y su tiempo", incluido en el número 24 (octubre de 1965).

16 El martinfierrismo es un movimiento de la segunda década del siglo XX que, como se conoce, el propio González Tuñón integró y que se conforma alrededor de la colección Martín Fierro (40 números, 1924-1927). Según consigna Jorge B. Rivera, la revista Martín Fierro es la continuación de un proyecto diseñado y llevado a cabo unos años antes por su director, el poeta Evar Méndez. En la primera versión, se perfila como "una publicación combativa, antigubernista y muy tocada por los sucesos represivos de la llamada Semana Trágica de ese año [1919], uno de los episodios sangrientos de la historia del movimiento obrero argentino" (Rivera, 1995:64). En su segundo trayecto, Martín Fierro se delinea, en cambio, como una publicación de corte literario. Participan de esta segunda etapa de la revista los poetas Oliverio Girondo, Enrique y Raúl González Tuñón, Jorge Luis Borges, entre otros.

17 Al respecto, cfr. en las Referencias bibliográficas Bonano (2016). 
concepción instrumental de la actividad estética, ni con el estilo de la crítica literaria que halla su razón última en la militancia partidaria.

\section{Improntas de la vanguardia histórica en El Barrilete. Juventud, irreverencia y antiacademicismo}

Impulsada y liderada por Roberto Jorge Santoro en su primera época, El Barrile$t e^{18}$ publica su primer número en agosto de 1963 y se extiende con un total de I3 números a lo largo de cuatro años hasta diciembre de 1967.9 Desde su nacimien- to, la revista propone la ampliación del público lector, ${ }^{20}$ con el objeto de llegar a sectores de la sociedad a los que habitualmente no alcanzan las revistas de poesías, dirigidas en general, según los editores advierten, a un lector más especializado.

La concepción de la creación simbólica como un trabajo semejante a cualquier otro aparece claramente especificada a lo largo de las páginas de la colección, ${ }^{21}$ al tiempo que el núcleo realizador se autorrepresenta como un grupo de auténticos «poetas del pueblo». Acorde con ello y en un movimiento semejante al delineado

18 Una aproximación más rigurosa al perfil de esta publicación está presente en el trabajo de nuestra autoría titulado "El poeta del pueblo/ la poesía para el pueblo. En torno al proyecto de El Barrilete (primera época)". Cfr. en Referencias bibliográficas, Bonano (2013).

19 Los cinco primeros, aparecidos mensualmente entre agosto y diciembre de 1963, llevaron el nombre de El Barrilete. Salimos a remontarnos y fueron dirigidos y editados por Roberto J. Santoro, mientras que Emilia de Santoro ocupaba el cargo de secretaria de Redacción. A partir del número seis, de febrero de 1964, la publicación adopta el nombre Barrilete y su portada se modifica, al tiempo que se incorporan páginas y secciones nuevas. Su dirección pasa a estar a cargo de un Consejo de Redacción integrado por Daniel Barros, Martín Campos, Ramón Plaza, Miguel Ángel Rozzini, Horacio Salas, Marcos Silber y Rafael Alberto Vásquez, además de Santoro. Desde este número seis, se edita con una frecuencia bimensual, a excepción de los números 12 y 13, de agosto-septiembre de 1966 y diciembre de 1967, respectivamente. El número 12 fue dirigido por Alberto Costa, Carlos Patiño, Felipe Reisin y Rafael Vásquez: el número 13 estuvo a cargo de Costa y Patiño. La publicación constó además de una segunda época con un número en octubre de 1968 (año V, N 1 ) y otro en septiembre de 1974 (año XII, $N^{\circ} 1$ ), este último editado en formato revista-sobre. Carlos Patiño y Alberto Costa dirigieron los números de esta segunda época; en 1974 Santoro se reincorporó a la dirección.

20 Con este propósito, el grupo editor moviliza una serie de acciones, tales como la organización de reuniones abiertas al público, dedicadas a la lectura oral y comentario de poemas, con debate, y la edición de los Informes, concebidos como folletos de poesía en torno de una problemática inmediata, ofrecidos en los kioscos a un precio muy bajo.

21 Por ejemplo, en la presentación que a modo de manifiesto el grupo despliega en el número 5: "no somos teóricos, por eso trabajamos, trabajamos y trabajamos. Nos ponemos sobrenombres, tenemos flacos, pelados, anteojudos, contadores, leguleyos, quinieleros; tenemos carreristas, fabricantes de fantasmas, ferroviarios, nos falta un basurero" (1963). 
por Hoy en la Cultura, El Barrilete aboga por el rescate de una tradición poética "popular», la que a ojos de los editores, nace de una conexión unívoca entre el escritor y el "pueblo», una cuestión a la que se concibe en la revista como históricamente desatendida por la crítica literaria canónica. Los homenajes que el grupo realiza a lo largo de sus I3 números a escritores y letristas de tango,así como su rescate de una línea de poemas de giros coloquiales, obedece a la voluntad de construcción de una genealogía que cuestiona la tradición letrada y permite al mismo tiempo legitimar la propia práctica, deudora de una poesía ligada a la «suerte del pueblo».

Algunos núcleos con los que El Barrilete comulga, se hallan próximos al modelo de poesía y de poeta delineado por las tendencias de vanguardia: juventud del escritor, atributo que se identifica con las actitudes de irreverencia y desenfado; impugnación del academicismo y del extranjerismo como rasgos de la crítica especializada; humanidad del poema (la poesía crea "un sublime de bolsillo»; «el poema no es realista sino humano»). Otros parecen en cambio alejarse de los credos vanguardistas:la obra "vive» en el contacto con el lector y se gesta en el «espíritu colectivo»; rechazo del artepurismo y requerimiento de un creador situado en la realidad de su tiempo, mezclado con ésta; reivindicación del «saber popular» en tanto materia del escritor y de una escritura "para el pueblo». ${ }^{22}$

Puede leerse en diálogo con el ideario estético e ideológico antes precisado, la atención que el grupo dispensa a las tendencias de vanguardias europeas y argentinas. Cabe señalarse aquí que a diferencia de la publicación impulsada por Orgambide, no se avizora prácticamente en El Barrilete la presencia de textos que reflexionen explícitamente sobre la poesía de vanguardia. Frente a ello, se constata en cambio la difusión en las páginas de la revista, de autores afines a tales tendencias. ${ }^{23}$ Toma interés en particular la atención concedida por los realizadores a una de las figuras más relevantes de la

22 Estas caracterizaciones de la labor son delineadas en los primeros cinco números de El Barrilete, a través de voces de autores externos tanto al grupo editor como al conjunto de los colaboradores asiduos. Pertenecientes a Miguel de Unamuno, Roberto Arlt, Vicente Huidobro, Antonio Machado y Rafael Barret, son recogidas en la página inicial de cada una de esas primeras cinco entregas.

23 En relación con los movimientos de vanguardia en Argentina, se registran poesías de Enrique González Tuñón, de Raúl G. Aguirre (impulsor y director permanente de la revista Poesía Buenos Aires), de Olga Orozco (ligada al surrealismo). En relación con las vanguardias históricas europeas, se recogen poemas de Tristán Tzara y Louis Aragon, al tiempo que estos últimos escritores son homenajeados por la revista. 
vanguardia hispanoamericana, el chileno Vicente Huidobro, cuyas ideas acerca de la actividad creadora son reproducidas en el número 3 (octubre de 1963). Precisamente, algunos de los núcleos seńalados más arriba son delimitados por Huidobro en el artículo de su autoría: la humanidad del poema y la impugnación del academicismo literario que, según se vio, $E l$ Barrilete reivindica en tanto gesto del poeta irreverente y crítico del statu quo.

En relación con las vanguardias europeas, la publicación reivindica el papel desempeñado por los poetas del «dadásurrealismo» francés, a cuyas figuras rinde breves homenajes. Desde una colocación discordante con la de Hoy en la cultura, no destaca, sin embargo, la militancia política o partidaria de los poetas pertenecientes al movimiento. La valoración positiva de poetas como Tristán Tzara o Louis Aragon, constituye en cambio, en El Barrilete, un gesto crítico del grupo realizador destinado a interpelar un modelo de escritor, aquel que se identifica con los ya mencionados núcleos «irreve- rencia» $\mathrm{y}$ «desenfado», en tanto actitudes indispensables del poeta cuya labor radica en impugnar lo establecido.

En la nota breve sin firma con que la revista homenajea a Tzara poco tiempo después de la muerte del escritor, el dadaísmo es caracterizado como «un movimiento estético que revolucionaría el mundo e indignaría a los burócratas del arte» (I964:5). Allí, el grupo editor vuelve a reconocerse en algunos de los rasgos que atribuye a Tzara (juventud, radicalidad) y toma posición al respecto: «Nosotros, en tanto jóvenes y poetas, no podemos dejar de recordar, aunque sea brevemente, a quien tratando de destruir la literatura, edificó una de las obras poéticas más importantes y bellas de nuestro tiempo" (5). Esta condición paradojal de la poesía de Tzara, parece dar cuenta de la idea que los propios realizadores tienen acerca de su tarea: la de impulsar una praxis simbólica susceptible de rechazar el orden instaurado y de proyectar a la vez una propuesta radical, sin que esta devenga luego en una retórica o en una institución.

24 Integran el grupo fundador y editor de Zona..., los poetas Edgard Bayley, Miguel Brascó, Ramiro de Casasbellas, Noé Jitrik, César Fernández Moreno, Francisco Urondo, y Alberto Vanasco. Participan también como editores de la revista Julio E. Lareu (en tres de los cuatro números) y el escultor Jorge Souza. Desde el número 2 de Zona..., se incorpora Zulema Katz como Secretaria. Cabe aclarar que si bien no existió la figura del director, tan corriente en este tipo de publicaciones, sí hubo responsables a cargo de cada uno de los números. Solo el primero estuvo supervisado por Vanasco y Brascó; los tres restantes, a cargo de Vanasco y Urondo. 
Disensos y continuidades. Zona de la poesía americana y las vanguardias argentinas de los '50

La trayectoria delineada por los poetas reunidos en los cuatro números de la revista Zona de la poesía americana ${ }^{24}$ difiere radicalmente de la trazada por los núcleos El Barrilete y Hoy en la Cultura. Así también, sus interpretaciones acerca de las vanguardias estéticas tanto como sus preferencias poéticas.

Perfilada como una revista de poesía atenta a las diversas formas del coloquialismo, Zona... propone un programa estético que Noé Jitrik sintetizó en los términos de una «cinta de Moebius entre la alta cultura y la cultura popular, desde lo más radical, que podía ser Macedonio, a lo más explícito, que podía ser Discépolo» (cit. en Freidemberg, I999b:I8). En el conjunto conformado por las figuras de Oliverio Girondo, Juan L. Ortiz, Macedonio Fernández y Enrique Santos Discépolo, homenajeadas en cada una de las portadas, parece plasmarse la propuesta que el grupo editor desarrolla a lo largo de los cuatro números aparecidos entre julio de 1963 y noviembre de 1964. Prepondera en los ensayos dedicados al género, la idea de que la "poesía nacional» no puede sino erigirse a partir de la confluencia entre la vanguardia - que desde la perspectiva de los realizadores, constituye la "poesía culta» o "poesía cultivada»— y la poesía conversacional o «popular», identificada en una de sus líneas con las poéticas del tango. ${ }^{25}$

Es a partir del posicionamiento antes precisado que puede indagarse en la presencia de las estéticas de vanguardia a lo largo de las páginas de la colección. Respecto de los poetas de vanguardia difundidos, resulta significativo el listado de escritores aparecido en el primer número. El mismo está dedicado a Girondo, quien asoma en la portada y es valorado por el grupo como el único miembro del movimiento martinfierrista que no abandonó a lo largo de los años su inicial espíritu renovador. Además de Girondo, se incluyen en este número, poemas de autores ligados al surrealismo argentino, entre ellos, Enrique Molina y Francisco Madariaga. Se recogen al mismo tiempo

25 En un trabajo previo de nuestra autoría (cfr. Bonano, 2012), hemos estudiado el proyecto de Zona... atendiendo a las modulaciones que adquieren en la revista las categorías "poesía cultivada", "alta cultura", "cultura popular". A partir de distintas aportaciones de la bibliografía, el examen mostró que la publicación delimita tales conceptos en los términos de esferas caracterizadas no tanto por rasgos intrínsecos o esencias determinadas, sino antes bien, por su mutuo antagonismo. Por otra parte, el concepto "cultura popular" es interpretado en la revista a veces como "dominación simbólica" y otras como el polo de una dicotomía en donde "lo popular" se asocia a ciertos rasgos o valores que permiten distinguir "lo propio", "lo nacional" de un "otro" representado por "lo antinacional" o "lo imperialista". 
reflexiones sobre la actividad creadora aportadas, entre otros, por Raúl G. Aguirre, el impulsor y director permanente de la revista Poesía Buenos Aires, experiencia en la que habían confluido cinco de los siete poetas editores de Zona....

La participación del grupo realizador en la experiencia invencionista liderada por Aguirre en la década de 1950, signa la mirada sobre las poéticas de vanguardia que los integrantes despliegan en sus ensayos. Como punto de partida, los animadores establecen que las tendencias líricas identificadas con la poesía de vanguardia han jugado en Argentina un papel preponderante para la conformación de una "poesía nacional»; sin embargo, a juicio de los editores, ellas no han logrado superar uno de los problemas que presenta la práctica lírica desde sus primeras manifestaciones: el de la desvinculación del escritor respectodel público y de las demás esferas de la sociedad. Teniendo en cuenta dicha proposición, se refieren a la labor de los invencionistas y de los surrealistas de las décadas de 1940 y $1950,{ }^{26}$ y consideran que si bien dichas experiencias dan cuenta de una «nueva sensibilidad" poética — preocupada por «expresar aquello que nos concierne; por obtener una forma propia de expresión»
(Urondo, 1963:14)—, se encuentran todavía aisladas del resto de la sociedad. Frente a ello, proponen recuperar «el don comunicativo, la función de la poesía» (Jitrik, I964:IO); solo así, entienden, los escritores hallarán el modo para religarse con el público e impulsar la constitución de una poesía nacional.

Es posible, en la dirección abierta por el párrafo anterior, establecer el sentido que adquiere el imperativo delimitado más arriba. Por un lado, los editores de Zona... retoman el movimiento presente en la tradición de las vanguardias históricas, consistente en la modernización de la lengua poética. En efecto, consideran que si hasta ese momento la poesía practicada por el oficialismo literario ha estado sujeta a los lineamientos impuestos por tendencias estéticas foráneas, el alcance de una forma propia de expresión sólo es posible mediante la creación o re-creación de la lengua literaria. Pero a diferencia del posicionamiento asumido por el escritor de vanguardia en los albores del siglo XX, esta experimentación no implica, en las conceptualizaciones de los integrantes de Zona..., la adopción de una perspectiva aristocratizante respecto de la lengua poética y, menos aún, la idea de repliegue del oficio a un lugar

26 Además del movimiento en torno de Poesía Buenos Aires, puede señalarse la presencia de otros grupos invencionistas y surrealistas reunidos en revistas como Arturo (1944), Cuadernos Invención (1946), Arte Madi (1947), Ciclo (1948), Contemporánea (1948), Conjugación de Buenos Aires (1951), A partir de cero (1952), Letra y Línea (1953). 
apartado del resto de la sociedad. ${ }^{27}$ De las vanguardias argentinas en el proceso manera semejante a Hoy en la cultura y El de constitución de una nueva poesía; por Barrilete, Zona... propone la apertura de el contrario, otorga a aquellas un papel la poesía a la realidad, pero a diferencia central en la medida en que las valora de las dos experiencias mencionadas en como «vanguardias vitales». primer término, no impugna el papel de

\section{Referencias bibliográficas}

Textos de El Barrilete, Hoy en la Cultura y Zona de la poesía americana

- AFLOJALE QUE COLEA (1963). El Barrilete. Salimos a remontarnos, (5), s/p.

- EDITORIAL (1961). Hoy en la Cultura, (1).

• GONZÁLEZ TUÑóN, R. (1964). Permanencia y mito. El surrealismo hoy. Hoy en la Cultura, (14), 4-5.

•- (1965). Crónica de César Vallejo y su tiempo. Hoy en la Cultura, (24), 11,12 y 18.

• HOMENAJE A TRISTÁN TZARA (1964). Barrilete, (6), 5.

- HUIDOBRO, V. (1963). Acerca de la poesía y los poetas. EI Barrilete. Salimos a remontarnos, (3), s/p.

- JITRIK, N. (1964). Poesía argentina entre dos radicalismos. Zona de la poesía americana, 3(I), 6-10.

- ROMÁN, M. (1963). Reflexiones y notas sobre el quehacer poético. Hoy en la Cultura, (9), 2-3.

- TANGO=POESÍA (1964). Hoy en la Cultura, (16), 14-15.

- STRADA, V. (1962). Vanguardia y decadentismo. Hoy en la Cultura, (6), 7.

- URONDO, F. (1963). La poesía argentina en los últimos años. Zona de la poesía americana, 2(I), 12-14.

27 Estos dos elementos caracterizan, según Edgardo Dobry, el ideario estético de las vanguardias poéticas que a partir del paradigma abierto por los cultores del simbolismo francés y por Stéphane Mallarmé en particular, propician el hermetismo lingüístico y el ejercicio de la vida interior. Ambos movimientos constituyen respuestas defensivas del poeta frente a la palabra circulante en el espacio público. 
Bibliografía general

- ALEMANY BAY, C. (1997). Poética coloquial hispanoamericana. Alicante: Universidad de Alicante Publicaciones.

- ANDRÉS, A. (1969). El 60. Buenos Aires: Editores Dos.

- BONANO, M. (2012). La propuesta de Zona de la poesía americana (Buenos Aires, 1963-1964): estéticas coloquiales y apropiaciones de la "cultura popular". Aisthesis. Revista Chilena de Investigaciones Estéticas, (52), 81-96.

-__ (2013). El poeta del pueblo/ la poesía para el pueblo. En torno al proyecto de El Barrilete (primera época). Orbis Tertius. Revista de Teoría y Crítica Literaria, XVII(19), 113-125. Recuperado de: http://www.orbistertius.unlp.edu.ar/article/view/ OTv18n19a09/4870

- _- (2016).Crítica de poesía y cultura política en la revista Hoy en la Cultura (Buenos aires, 1961-1966). Revista de Literaturas Modernas, 46(1), 21-42.

- BÜRGER, P. (1987). Teoría de la vanguardia (2000). Historia, ciencia, sociedad, 206. Barcelona: Península.

- CALABRESE, E. (2006). Crítica y poesía. Elementos para una tradición. Orbis Tertius. Revista de Teoría y Crítica Literaria, XI(12). Recuperado de: www.orbistertius.unlp.edu.ar/article/ view/OTv11n12a09/3782

- CALBI, M. (1999). Prolongaciones de la vanguardia. En Jitrik, N. (Dir.). Historia crítica de la literatura argentina, 10: Cella, S. (Dir. del volumen), La irrupción de la crítica (pp. 235-255). Buenos Aires: Emecé.

- DALMARONI, M. (1993). Juan Gelman. Contra las fabulaciones del mundo. Buenos Aires: Almagesto.

- _ (2002). Juan Gelman: del poeta-legislador a una lengua sin estado. Orbis Tertius. Revista de Teoría y Crítica Literaria, (8), 117-136.

-_ (2012). De aquel joven poeta comunista. Una relectura desde los comienzos. En Salazar Anglada, A. (Comp.). Juan Gelman: gramática y poética contra el olvido. Sevilla: Servicio de Publicaciones de la Universidad de Sevilla. Recuperado de: http:// lectorcomun.com/miguel-dalmaroni/papeles-sueltos/191/de- 
aquel-joven-poeta-comunista-una-relectura-desde-los-comienzos/ -__ (2004). La palabra justa: Literatura, crítica y memoria en la Argentina. 1960-2002. Santiago de Chile: Ril-Melusina. - DOBRY, E. (2007). Orfeo en el kiosco de diarios. Ensayos sobre poesía. Buenos Aires: Adriana Hidalgo.

- FREIDEMBERG, D. (1999a). Herencias y corte. Poéticas de Lamborghini y Gelman. En Jitrik, N. (Dir.), Historia crítica de la literatura argentina, 10: Cella, S. (Dir. del volumen). La irrupción de la crítica (pp. 183-209). Buenos Aires: Emecé.

- __ (1999b). Cronología. Dossier Urondo. Diario de Poesía, (49), 15-25.

- GARCÍA HELDER, D. (1999). Poéticas de la voz. El registro de lo cotidiano. En Jitrik, N. (Dir.), Historia crítica de la literatura argentina, 10: Cella, S. (Dir. del volumen). La irrupción de la crítica (pp. 213-234). Buenos Aires: Emecé.

- MASIELLO, F. (1985). Argentine Literary Journalism: The production of a Critical Discourse. Latin American Research Review, $X X(I), 27-60$.

- PORRÚA, A. (1987). Notas sobre la poética del 60. En AA. VV. (Comps.). Actas del IV Congreso Nacional de Literatura Argentina III (pp. 105-117). Universidad Nacional de Cuyo.

-__ (1992). Relaciones de Juan Gelman: el cuestionamiento de las certezas poéticas. Revista de crítica literaria latinoamericana, 35(XVIII), 61-70.

-__ (2001). Variaciones vanguardistas. La poética de Leónidas Lamborghini. Rosario: Beatriz Viterbo.

- _ (2002). Una poética del pliegue. Orbis Tertius. Revista de Teoría y Crítica Literaria, (8), 137-148.

- RIVERA, J.B. (1995). El periodismo cultural. Buenos Aires: Paidós.

- ROMANO, E. (1983). Sobre poesía popular argentina. Buenos Aires: CEDAL.

- SALAS, H. (1975). Generación poética del 60. Buenos Aires: Ediciones Culturales Argentinas.

- TERÁN, O. (1991). Nuestros años sesentas. La formación de la nueva izquierda intelectual en la Argentina, 1956-1966. Buenos Aires: Puntosur. 